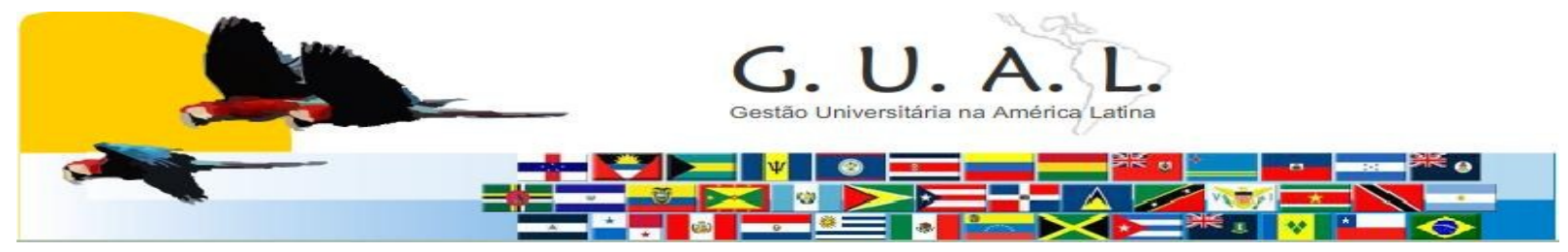

ISSN 1983-4535

\title{
AS POLÍTICAS PÚBLICAS DE ENSINO SUPERIOR TECNOLÓGICO E A QUESTÃO DA RESPONSABILIDADE SOCIAL NO BRASIL
}

\author{
Marcus Vinicius de Oliveira Brasil, Mestre \\ Universidade de Fortaleza/UNIFOR \\ mvobrasil@gmail.com \\ Maria Engracia Loiola, Mestre \\ Instituto Federal de Educação, Ciência e Tecnologia do Ceará/IFCE \\ engracia.loiola@ig.com.br \\ Mônica Mota Tassigny, Doutora \\ Universidade de Fortaleza/UNIFOR \\ monica.tass@gmail.com
}

\begin{abstract}
RESUMO
Este artigo objetivou debater a viabilidade das políticas públicas de ensino superior tecnológico no Brasil e algumas de suas prerrogativas para a responsabilidade social das instituições de ensino superior. Nesta direção, discutiram-se as principais políticas públicas voltadas para o ensino tecnológico, particularmente, ressaltou-se o caso do Estado do Ceará e as possibilidades do ensino superior tecnológico ser princípio da politecnia. Tratou-se de pesquisa bibliográfica e documental. Conclui-se que as políticas públicas de ensino superior tecnológico no nosso país têm avançado na formação de pessoal qualificado para o mundo do trabalho, porém existe ainda um elo perdido entre a teoria e a praxis da responsabilidade social que precisa ser recuperado como condição sine qua non para a legitimação de uma efetiva Política de Estado.
\end{abstract}

Palavras-chave: Educação superior. Ensino tecnológico. Políticas públicas. Responsabilidade social. 


\section{AS POLÍTICAS PÚBLICAS DE ENSINO SUPERIOR TECNOLÓGICO E A QUESTÃO DA RESPONSABILIDADE SOCIAL NO BRASIL}

\section{INTRODUÇÃO}

As políticas públicas têm sido tema de discussão em várias mesas de debates, seja de políticos ou no cotidiano popular. $\mathrm{O}$ assunto, no tocante a ensino superior tecnológico, parece emitir conclusões ou percepções das mais diversas, seja onde for discutido. Torna-se necessária uma reflexão científica sobre o tema, à luz dos teóricos que abordam o assunto e das próprias políticas que norteiam o processo.

Este artigo científico teve como alvo principal debater a viabilidade das políticas públicas de ensino superior tecnológico no Brasil e algumas de suas prerrogativas para a responsabilidade social das instituições de ensino superior. Ainda, neste ensaio teórico discutiram-se as principais políticas públicas voltadas para o ensino tecnológico, particularmente, ressaltou-se o caso do Estado do Ceará e as possibilidades do ensino superior tecnológico ser princípio da politecnia.

A parte exploratória da pesquisa foi feita utilizando levantamentos em fontes secundárias. As técnicas estão relacionadas com a parte prática da coleta de dados em uma pesquisa científica, sendo um conjunto de processos que servem a determinado fim (LAKATOS; MARCONI, 1991). Ainda, foi feita uma pesquisa documental das políticas públicas de Estado relacionadas à educação profissional superior.

Atitudes sócio e ambientalmente responsáveis em Instituições de Ensino Superior ${ }^{\mathrm{i}}$ dizem respeito ao conjunto de práticas (e gestão) que contribuem para a edificação de uma sociedade mais justa, um meio ambiente mais saudável, tendo como base, ações orientadas para a igualdade de chances, a inclusão social e o desenvolvimento sustentável.

Este conceito de gestão responsável é resultado de um movimento de conscientização recente, nos meios empresariais num primeiro momento e depois nos meios acadêmicos. Sobre este particular, alguns setores empresariais corroboraram com a tese de que cabe sim ao governo promover ações capazes de distribuição de bens sociais, entretanto, há nova missão para as organizações, e não importa sua natureza (pública ou privada), urge sua cooperação mais atuante com a coletividade.

Mundialmente $^{\mathrm{ii}}$, observa-se que este fenômeno tem sido incentivado pelo setor empresarial que vem se adequando, progressivamente, a esta nova postura de compromisso direto com as questões sociais na adoção de comportamento responsável perante a comunidade. Nos meios universitários, trata-se do engajamento do ensino, da pesquisa e da 


\section{AS POLÍTICAS PÚBLICAS DE ENSINO SUPERIOR TECNOLÓGICO E A QUESTÃO DA RESPONSABILIDADE SOCIAL NO BRASIL}

extensão em gestões que englobam o atendimento de questões sociais emergentes como um de seus objetivos e que deve ser desenvolvida pelo estabelecimento de parcerias e pelo diálogo social na consecução dos fins do desenvolvimento com sustentabilidade. Neste sentido, é a partir de princípios e pressupostos que se formam competências de uma universidade sócio e ambientalmente responsável (DESAULNIERS, 2006).

\section{O ENSINO SUPERIOR E A RESPONSABILIDADE SOCIAL NO BRASIL}

Efetivamente, partir de $2005^{\mathrm{iii}}$, a responsabilidade social passou a ser uma das dimensões analisadas a partir do instrumento de avaliação do Sistema Nacional de Avaliação Superior (SINAES). Foram implementados outras ações, como avaliação externa como o Exame Nacional de Avaliação do Ensino Superior (ENADE) e do Exame Nacional do Ensino Médio (ENEM). Esses instrumentos tem como prerrogativas a exigência de avaliações internas e externa, focando a qualidade da educação. Essa, por sua vez, liga-se, não raras às vezes, as ações de responsabilidade das instituições de ensino superior.

Tendo em vista o ensino superior brasileiro, de um modo geral, pode-se afirmar que a responsabilidade social universitária, constitui uma das exigências da inclusão social, do desenvolvimento econômico e da defesa do meio ambiente (BOLLAN; DA MOTTA, 2008). Algumas das principais estratégias de gestão ambiental e de responsabilidade social que podem ser aplicáveis às Instituições de Ensino Superior: "os projetos sociais em meio ambiente; educação; saúde; cultura; de apoio à criança e o adolescente; em voluntariado e a imagem ambiental para fins de marketing." (TACHIZAWA, 2002, p. 287-288).

Contudo, a melhor caracterização destas ações revela um estreito compromisso das universidades com a sociedade como finalidade institucional e acadêmica e como meio do cumprimento da tríplice função universitária de: ensino, pesquisa e extensão.

A organização corporativa em torno de uma gestão responsável ainda constitui um movimento recente no setor educacional, entretanto, sua efetivação e universalização em território brasileiro são urgentes, pois apenas 12,81\% dos jovens entre 18 e 24 anos estão matriculados no ensino superior e menos de 50\% entre 15 e 17 anos frequentam a escola (IBGE, 2003).

Este fato por si só já sugere a responsabilidade universitária como uma necessária praxis formadora de profissionais com forte formação ética e cidadã e, ao mesmo tempo, 


\section{AS POLÍTICAS PÚBLICAS DE ENSINO SUPERIOR TECNOLÓGICO E A QUESTÃO DA RESPONSABILIDADE SOCIAL NO BRASIL}

passa a ser uma demanda mundial, como perspectivas de combate aos efeitos negativos da globalização. A surpreendente obsolescência do conhecimento e das tecnologias de um lado, e de outro, a secular academia, deve ser repensada mundialmente quanto a suas missões institucionais. A educação superior no Brasil tem acompanhado este movimento global de reflexão sobre as novas determinações e sobre o papel social e vem instituindo uma série de medidas de flexibilização (na gestão, na didática, nas metodologias etc), e na função de democratização do acesso à ciência no ensino superior.

Conclui-se que nem sempre a viabilidade técnica de um projeto de implementação de políticas públicas está atrelada a sua viabilidade política. É necessária uma disposição do Estado em investir mais recursos no ensino tecnológico, não só por causa das leis de mercado, mas para desenvolver o ser social em sua totalidade.

No nosso país, muitas de nossas instituições continuam omissas diante de nossa realidade econômica e social local e os desafios regionais e nacionais, frente ao mercado global e a participação ativa na luta contra a exclusão social. Contudo, como em outros países, o setor universitário brasileiro começa a se organizar para esta nova realidade educacional. Certamente, se não é a única solução para a grande incerteza que desafia o futuro das universidades, poderá ser um caminho de orientação que deve alicerçar a reestruturação da educação superior em direção ao crescimento com sustentabilidade.

\subsection{Educação e as políticas públicas de Estado}

A educação pública e o Estado são palcos sociais nos quais as lutas pela apropriação do conhecimento entre classes sociais estão em permanente conflito. De acordo com Holanda (2002), a organização de ofícios, segundo o modelo imposto pelo reino português para o Brasil, foi profundamente influenciada pelo trabalho escravo e pela indústria caseira, que acabava por entravar o comércio, sem falar na escassez de artífices livres em grande parte das vilas e cidades, colaborando assim para a classe economicamente favorecida.

Conforme Melo (1999, p.13) “a política social se inscreve na agenda de intervenção do Estado brasileiro no quadro das transformações associadas à Revolução de 30 e à Era Vargas”. Apesar da existência da intervenção estatal desde da década de 30 pela elaboração de políticas públicas, somente na década de 1980 é que surgem os primeiros modelos da avaliação de políticas públicas. De acordo com Azevedo (1993. p.739), o ensino profissional é 


\section{AS POLÍTICAS PÚBLICAS DE ENSINO SUPERIOR TECNOLÓGICO E A QUESTÃO DA RESPONSABILIDADE SOCIAL NO BRASIL}

primordialmente um dever do Estado, objetivando favorecer as classes menos abastadas, cumprindo ao Estado a responsabilidade das iniciativas.

Formulada pelo Lord Keynes, a intervenção moderada do Estado na economia permitindo o livre mercado, acabou por ajudar a fundar o Estado do bem-estar, com "a idéia de compatibilidade (ou até complementaridade) entre crescimento econômico e políticas sociais, entre acumulação e legitimação, entre capitalismo e democracia" (SANTOS, 1990, p.196). Furtado (2003, p.4) afirma que "a versão brasileira da política Keynesiana foi introduzida pela Comisión Económica para a América Latina y el Caribe (CEPAL), através da política de desenvolvimentista do governo Kubitschek, a partir dos anos 50”. Na visão de Carvalho (1996, p.19) “ [...] no lugar de um Estado Keynesiano de primazia das políticas sociais [...] emerge o Estado Schumpeteriano, centrado na inovação e na competitividade, dando primazia a política econômica, em detrimento de políticas sociais”.

Para a maioria dos Estados Nacionais, ao confrontar os interesses locais com os da economia globalizada fica difícil posicionar-se sem que para isso haja uma perda de autonomia (STUBBS; UNDERHILL, 1994, p.422). "Ou seja: a tendência para a globalização vem sendo acompanhada, também, por uma tendência à regionalização da economia mundial, através da formação de áreas de livre comércio, de uniões alfandegárias e de mercados comuns" (GALVÃO ; VERGOLINO, 2004, p.42).

\subsection{O Nordeste, a educação e o Estado do Ceará}

A região Nordeste do Brasil possui um alto nível de pobreza, e o Ceará tem $95 \%$ do seu território no semiárido, com adversidades climáticas e nível educacional baixo. O Plano de Desenvolvimento Sustentável do Ceará, para o período 1999 a 2002, apontou que:

O índice de desenvolvimento humano do Ceará (0,590-PNUD/IPEA, 1996), abaixo do registrado para o Brasil (0,830-PNUD/IPEA,1996), tem sido fortemente condicionado pela situação educacional do Estado. O baixo nível de instrução da população, por seu turno, se reflete também na sua baixa capacitação, dificultando a criação de novas alternativas de superação das dificuldades e carências sociais, deixando de contribuir no combate à crise do mercado de trabalho (CEARÁ, 1999-2002).

As transformações socioeconômicas que estão acontecendo no País têm provocado profundas modificações no mercado de trabalho, que passou a exigir pessoal qualificado e 


\section{AS POLÍTICAS PÚBLICAS DE ENSINO SUPERIOR TECNOLÓGICO E A QUESTÃO DA RESPONSABILIDADE SOCIAL NO BRASIL}

atualizado para atender às demandas diversificadas das atividades, à evolução dos processos tecnológicos e às novas especializações exigidas pelo programa de desenvolvimento sustentado proposto pelo Governo do Estado do Ceará, com o apoio do setor privado. Para Ala-Harja e Helgason (2000, p.9) "Entende-se por programa um conjunto de atividades organizadas para realização dentro de cronograma e orçamentos específicos do que se dispõe para a implantação de políticas [...]”

Paralelamente, a abertura do mercado aos produtos importados obriga as empresas a reciclarem os seus empregados, a adaptarem as suas estruturas à nova realidade e, sobretudo, a concentrarem esforços em busca de maiores índices de produtividade e de melhores padrões de qualidade e de controle da poluição, o que lhes asseguram a competitividade necessária à sobrevivência e à conquista de novos mercados para a comercialização dos seus produtos, trazendo, em consequência, a melhoria da qualidade de vida da população.

Devido a ausência de uma política industrial de longo prazo para a Região que agregasse a economia nordestina à nacional, fez surgir através dos estados nordestinos, políticas locais de atração de investimentos industriais. Por causa da grande diferenciação regional dentro do Nordeste, torna-se necessário um novo critério de regionalização, que permita estabelecer diretrizes de política direcionadas e coerentes com os objetivos específicos para cada conjunto de regiões ou localidades (FONTENELE; MELO, 2003, p. 56; DINIZ ; BASQUES, 2004, p. 92).

Segundo Faleiros $(1988$, p.8) “[...] políticas sociais ora são vistas como mecanismo de manutenção da força de trabalho, ora como conquistas dos trabalhadores, ora como arranjos do bloco do poder ou bloco governante [...]". Os cursos, dirigidos à formação e à requalificação profissionais, visam atender às demandas do mercado de trabalho, no que tange às áreas de execução e operacionalização de tarefas técnicas, tanto do setor de produção quanto dos projetos de desenvolvimento em implantação ou a serem implantados, de acordo com as prioridades definidas no Plano de Governo do Estado do Ceará.

A prática da avaliação envolve a combinação de métodos, critérios e abordagens múltiplas, devendo ter um componente metodológico rigoroso, para fins de validação e credibilidade. A avaliação como instrumento de planejamento e gestão auxilia na tomada de decisão. Deve-se responder as seguintes perguntas: quem deve ser avaliado? para que avaliar? o que avaliar? quando avaliar? como tratar os dados? como interpretar os resultados e como 


\section{AS POLÍTICAS PÚBLICAS DE ENSINO SUPERIOR TECNOLÓGICO E A QUESTÃO DA RESPONSABILIDADE SOCIAL NO BRASIL}

disseminar os produtos da avaliação? É necessário tomar cuidado na avaliação de políticas públicas para não exacerbar a preocupação com questões de rentabilidade econômica em detrimento da rentabilidade social dos programas (VIANNA, 2005; GOMES, 2002).

Segundo Freire $(2005$, p.17) “A avaliação de resultado e de impacto é realizada após a conclusão do programa ou projeto e objetiva medir a efetividade do programa bem como as mudanças na realidade sobre a qual o programa incide". Isso é possível comparando a situação na dimensão escolhida após a implementação do programa com a situação hipotética sem a existência do programa. A avaliação de impacto pode ser dimensionada nos aspectos sociais, econômicos, institucionais, ambientais.

De acordo com Belloni (2003), avaliar é um processo sistemático de análise de uma política e seus impactos sociais. Portanto, avaliar não se reduz a comparar o proposto e o realizado, ou seja, a constatação do atingimento de metas de uma política ou plano, mas vai além, ao subsidiar elementos em vista ao melhoramento das atividades envolvidas.

Quanto ao momento, a avaliação pode ser ex-ante e ex-post, sendo a primeira realizada nas fases de desenho ou formulação, ou seja, antes da implementação do programa ou projeto; e a segunda, é efetuada durante e depois do estágio de implementação do mesmo. Enquanto a primeira verifica a questão da viabilidade, a última se preocupa com os resultados, impactos e efeitos (FREIRE, 2005, p. 15-16).

\subsection{Ensino Tecnológico no Ceará}

Segundo Bastos (1991, p.51) “o ensino politécnico está fundamentado, sem dúvida, na concepção marxista da educação que, por sua vez, considera o trabalho como primeira e essencial instância educativa". Não devendo consistir apenas no domínio da técnica, mas é necessário ter uma consciência crítica, ultrapassando a manipulação de máquinas e ferramentas.

Conforme Arrais Neto (2002, p.2), a politecnia na lógica dialética "Representa uma realidade em que o trabalhador domina o processo de trabalho, sob a forma de conhecimento científico e tecnológico necessário à ação produtiva, e sob a forma de organização autônoma da produção". Desta forma, o trabalhador deixa de ser um mero executor de tarefas, como era na concepção fordista. De acordo com Minayo (1994, p.24) a abordagem dialética “ [...] 


\section{AS POLÍTICAS PÚBLICAS DE ENSINO SUPERIOR TECNOLÓGICO E A QUESTÃO DA RESPONSABILIDADE SOCIAL NO BRASIL}

propõe abarcar o sistema de relações que constrói o modo de conhecimento exterior ao sujeito, mas também de representações sociais que traduzem o mundo dos significados."

Conforme as Diretrizes Curriculares Nacionais definidas pelo Conselho Nacional de Educação, os Cursos Superiores de Tecnologia são legalmente cursos regulares de graduação, permitindo todo tipo de pós-graduação. A educação profissional é orientada pelo Decreto Federal n $n^{\circ} 5.154$ de 23 de julho de 2004. “Ou seja, a legislação é um instrumento importante para compreender a política educacional e, consequentemente, o planejamento" (VIEIRA e ALBUQUERQUE, 2001, p. 27).

A formação superior que se refere o decreto supra-citado, está focada no cabedal de conhecimentos científicos e tecnológicos aplicados a uma ou mais áreas profissionais, buscando o desenvolvimento de aptidões relacionadas ao uso de tecnologias e a geração de inovações.

Na realidade, a formação de tecnólogos e pós-graduados desses cursos pode enfrentar problemas, tais como: restrições à habilitação profissional de tecnólogo e a expectativa de níveis salariais mais baixos em comparação aos cursos de graduação plena. Por outro lado, esses cursos respondem aos anseios dos estudantes que querem uma formação mais flexível, mais curta e com maior aplicação no mercado de trabalho.

O cenário educacional no Ceará que, nestes últimos anos, considerou a educação como “mola mestra" para o desenvolvimento, pelo ao menos era o discurso das políticas públicas anteriores, senão vejamos:

[...] elevar o nível educacional, cultural, e tecnológico do homem cearense, para que ele possa assumir o seu destino. Para isso, é necessário pensar-se não apenas num horizonte de quatro anos, mas no horizonte de uma geração. $\mathrm{O}$ atual Governo pretende iniciar um processo irreversível, no sentido de universalizar o acesso à escola, melhorando a qualidade do ensino e garantindo oito anos de permanência mínima do aluno no sistema escolar. Não serão medidos esforços para a promoção da revolução educacional no Estado. A implantação de uma nova escola, que coloque os conhecimentos técnicos à serviço do povo, é a diretriz básica para as ações educacionais do Governo ( BRASIL apud QUEIROZ, 2007, s/p)

De acordo com a autora (2007) no Plano de Mudanças, seus elaboradores, indicavam que havia um grande distanciamento entre as atividades científicas e tecnológicas e os problemas da comunidade cearense. No diagnóstico realizado por ocasião de sua elaboração, o governo estadual percebeu que as condições estruturais e recursos humanos, para operar tais

Rev. GUAL., Florianópolis, v.4, n. 2, p. 219-233, mai/ago. 2011 


\title{
AS POLÍTICAS PÚBLICAS DE ENSINO SUPERIOR TECNOLÓGICO E A QUESTÃO DA RESPONSABILIDADE SOCIAL NO BRASIL
}

mudanças existiam no âmbito das universidades, faltando, contudo, uma articulação dos órgãos responsáveis e a existência de uma política priorizando as necessidades da população. Sobre isso explicitou o Plano:

\begin{abstract}
$\mathrm{Na}$ área de recursos humanos, dispõe-se, entre universidades e órgãos estaduais e federais, de um considerável número de cientistas e pesquisadores de elevada qualidade. Somente na UFC há cerca de mil professores e pesquisadores, dos quais mais de $50 \%$ são titulados com cursos de especialização, mestrado e doutorado. As demais instituições da área de Ciência e Tecnologia se ressentem de adequados programas de capacitação e treinamento. De vez que, nessas instituições, apenas $30 \%$ de seu pessoal têm curso de especialização (CEARÁ, 1987-1991, p. 165).
\end{abstract}

Segundo o mesmo documento, a produção científica e tecnológica teria relação com as demandas de cada região:

\begin{abstract}
As ações a serem implementadas em termos de produção científica e tecnológica obedecerão a critérios de prioridade de acordo com as demandas de cada região objetivando o aproveitamento integrado das oportunidades econômicas existentes, ensejando a elevação nos níveis de emprego e renda. O modelo da intervenção ora previsto priorizará a geração de tecnologias voltadas para o aproveitamento econômico do semi-árido através da agropecuária adaptada, da indústria (especialmente a mineração), e da adaptação e descoberta de processo alternativos de geração de energia. Ênfase especial será dada também à pesquisa na área de irrigação, principalmente a geração de técnicas adequadas à pequena produção agrícola e agro-industrial, no sentido de promover a aglutinação de pequenos negócios em espaços econômicos (BRASIL, 1987-1991, p. 165).
\end{abstract}

Compreendemos a Educação Profissional Tecnológica, não como mantenedora de um modelo de desenvolvimento assentado na visão anterior, mas na busca de, caso necessário, denunciar os conceitos de educação, técnica e tecnologia a elas propostos, qual seja a visão neutra, para ser "eficiente" e "eficaz" para atuar e responder as necessidades do mercado. Nossa reflexão toma por base a compreensão de que a técnica: [...] não se resume à invenção e uso de um instrumento. Ela tem a característica marcante de que, uma vez inventado o primeiro instrumento, desencadeia-se um processo de melhora de suas formas e usos para satisfazer necessidades crescentes da humanidade (VARGAS apud QUEIROZ, 2007, s/p)

Nessa compreensão, a educação tecnológica precisa ter como resposta a busca permanente de:

[...] formar um indivíduo, na sua qualidade de pessoa humana, mais crítico e

Rev. GUAL., Florianópolis, v.4, n. 2, p. 219-233, mai/ago. 2011 
consciente para fazer a história do seu tempo com possibilidade de "construir" novas tecnologias, fazer uso da crítica e da reflexão sobre a sua utilização de forma mais precisa e humana, e ter as condições de, convivendo com o outro, participando da sociedade em que vive, transformar essa sociedade em termos mais juntos e humanos. Há momentos de conhecimento da tecnologia, de sua relação com a ciência, da compreensão do binômio: tecnologia e progresso e suas repercussões nas relações sociais (GRINSPUN apud QUEIROZ, 2007, p.29 ).

Com esse entendimento, temos que analisar as instituições escolares pesquisadas na perspectiva de que educação, ciência e tecnologia não podem ser vistas de forma separada do contexto social e que em educação sistematizada não se pode falar de "neutralidade" científica ou de estudo de tecnologia, sem as bases científicas.

Discorrendo sobre inovação, Schumpeter descreveu a evolução tecnológica como uma destruição criativa. Na busca pelo novo, deve-se repensar o que for velho e ultrapassado, na tentativa de reorientar a produção (SCHUMPETER,1984).

As duas maiores implicações dessa evolução são: os empreendedores, que ao contrário dos gerentes, arriscam mais pelo uso da criatividade gerando inovações. E como a inovação leva tempo para sua consecução, os capitalistas de risco ao conferirem crédito aos empreendedores compartilham riscos calculados (ROSTOW, 1990).

De acordo com Belloni (2003, p. 38) o conceito de empregabilidade “ [...] é entendido não apenas como a capacidade de obter um emprego, mas sobretudo de se manter em um mercado de trabalho em constante mutação”. Le Boterf (2000) analisa que é imprescindível a obtenção de um diploma, mesmo que não garanta uma vaga de emprego, porém aquele pode evitar a exclusão do mercado de trabalho. Os cursos Superiores de Tecnologia são de graduação, os graduados nestes cursos denominam-se "tecnólogos", sendo considerados profissionais de nível superior, tendo formação direcionada para uso e geração de tecnologias, bem como a gestão empreendedora de produtos e serviços. Duas forças moldam os sistemas escolares: uma delas no sentido de garantir mobilidade social, oportunidade e igualdade de direitos; e outra no sentido da empregabilidade, treinando o trabalhador e propiciando acumulação de capital (CARNOY; LEVIN apud MORROW ; TORRES, 1997). 


\section{AS POLÍTICAS PÚBLICAS DE ENSINO SUPERIOR TECNOLÓGICO E A QUESTÃO DA RESPONSABILIDADE SOCIAL NO BRASIL}

\section{CONSIDERAÇÕES FINAIS}

Conclui-se que nem sempre a viabilidade técnica de um projeto de implementação de políticas públicas está atrelada a sua viabilidade política. É necessária uma disposição do Estado em investir mais recursos no ensino tecnológico, não só por causa das leis de mercado, mas para desenvolver o ser social em sua totalidade.

É mais fácil criticar as iniciativas relacionadas ao ensino superior tecnológico no Brasil e no Ceará, do que apontar soluções para o problema do emprego e renda. É patente a necessidade deste tipo de ensino principalmente oferecido pelo Estado.

Pode-se verificar que o mercado de trabalho para egressos de cursos superiores de tecnologia é crescente, basta um olhar no cotidiano dos principais jornais do Ceará, para constatação de um grande número de anúncios requisitando este tipo de mão-de-obra. Porém, a alta demanda de mercado não é suficiente para explicar as questões que envolvem o tema. Por isso, este artigo científico procurou fazer uma reflexão envolvendo as políticas públicas que fundamentam a prática social.

É incontestável que sempre se ouvirá algum tipo de crítica envolvendo as práticas governamentais, mas é preciso se deter um pouco mais na discussão científica do assunto, lembrando que essas práticas não devem ser descontinuadas. Principalmente no tocante as verbas para a manutenção e expansão desse tipo de ensino, pois as mesmas devem ser objeto de preocupação do Estado brasileiro, embasadas não somente em informações de mercado, mas principalmente na prática desenvolvimentalista de governos sincronizados com as necessidades da sociedade e no rompimento de novas fronteiras de ciência e tecnologia. Conclui-se que a visão social deve nortear essas políticas públicas e não somente as leis de mercado. No nosso país, muitas de nossas instituições continuam omissas diante de nossa realidade econômica e social local e os desafios regionais e nacionais, frente ao mercado global e a participação ativa na luta contra a exclusão social. Contudo, como em outros países, o setor universitário brasileiro começa a se organizar para esta nova realidade educacional. Certamente, se não é a única solução para a grande incerteza que desafia o futuro das universidades, poderá ser um caminho de orientação que deve alicerçar a reestruturação da educação superior em direção ao crescimento com sustentabilidade.

Rev. GUAL., Florianópolis, v.4, n. 2, p. 219-233, mai/ago. 2011 


\title{
AGRADECIMENTOS
}

Sinceros agradecimentos a Fundação Cearense de Amparo à Pesquisa- FUNCAP pelo fomento à pesquisa.

\section{REFERENCIAS}

ALA-HARJA, Marjukka; HELGASON, Sigurdur. Em direção às melhores práticas de avaliação. Revista do Serviço Público/Fundação Escola Nacional de Administração PúblicaBrasília: n. 4, p. 5-59, out. 2000.

ARRAIS NETO, Enéas; PINA, Manoel José; FELISMINO, Sandra Cordeiro (Orgs.) Trabalho e Educação face à crise global do capitalismo. Fortaleza: LCR, 2002 (Coleção Diálogos Intempestivos).

AZEVEDO, Fernando de. A cultura brasileira: introdução ao estudo da cultura no Brasil. Brasília: Ed. da Universidade de Brasília, 1993.

BASTOS, J.A. de S. L. de A. A educação técnico-profissional: fundamentos, perspectivas e prospectivas. Brasília:SENETE, 1991.

BELLONI, Isaura; MAGALHÃES, Heitor de e SOUSA, Luiza Costa de. Metodologia de avaliação em políticas públicas: uma experiência em educação profissional. 3 ed. São Paulo: Cortez, 2003 (Coleção Questões da Nossa Época; v.75).

BOLlAN, V.; DA MOTTA, M. V. Responsabilidade Social no Ensino Superior. In: Responsabilidade Social. São Paulo: ABEMES, 2008, Vol.3, jun.

\begin{abstract}
BRASIL. INSTITUTO BRASILEIRO DE GEOGRAFIA E ESTATÍSTICA (IBGE). Contas Regionais do Brasil 2003. Disponible: $>\mathrm{http} / / \mathrm{www}$. ibge.gov.br/home/estatistica/população/condicaodevida/indicadoresminimos/sinteseindcsoc iais2004/indic_sociais2004.pdf,09/16/2005.
\end{abstract}

CARVALHO, Alba Pinho de. O cenário das políticas sociais no Brasil hoje: gestão e controle social. Fortaleza, 1996 (mimeo).

CEARÁ. Governador, 1999-2002 (Tasso Jereissati). Consolidando o novo Ceará: Plano de desenvolvimento sustentável 1999-2002. Fortaleza: SEPLAN, 2000.

CEARÁ. Plano de Mudanças - 1987/1991). Fortaleza: Governo do Ceará, 1987.

DESAULNIERS, J. R. Responsabilidade Social \& Univeridade. Canoas/Rio Grande do Sul: ULBRA/EDIPUCRS, 2008. 
DINIZ, C.C.; BASQUES, M. F. D. A industrialização nordestina recente e suas perspectivas. Fortaleza: Banco do Nordeste do Brasil, 2004.

FALEIROS, V.P. O que é política social. São Paulo: Brasiliense,1988.

FONTENELE, A. M.; MELO, Maria Cristina Pereira de. Inserção internacional da Economia Cearense: potencialidades e limites para o crescimento. Fortaleza: Banco do Nordeste, 2003.

FREIRE, Laura Lúcia Ramos. Modelo de avaliação do PRODETUR/NE-III: base conceitual e metodológica. Fortaleza: Banco do Nordeste do Brasil, 2005 (Série Documentos do Etene; n.03).

FURTADO, Maria Isabel de Araújo. Evolução das idéias sociais. 2003 (Mimeo).

GOMES. C.M. Processo de trabalho e processos de conhecimento. IN: GOMES, C.M. et alii. Trabalho e conhecimento: dilemas na educação do trabalhador. São Paulo, Cortez, 2002.

HOLANDA, Sérgio Buarque. Raízes do Brasil. $26^{\text {a }}$ ed. São Paulo: Companhia da Letras, 2002.

LAKATOS, E. M.; MARCONI, M. Fundamentos de metodologia científica. 3 ed. São Paulo: Atlas, 1991.

LE BOTERF, Guy. Construire les compétences individuelles et collectives. Paris: Éditions d'Organisation, 2000.

MELO, André Marcus. As sete vidas da agenda pública brasileira IN: RICO, Elizabeth Melo (Org.). Avaliação de políticas sociais: uma questão em debate. 2 ed. São Paulo: Cortez: Instituto de Estudos Especiais, 1999.

MINAYO, M.C.S. Pesquisa Social, teoria, método e criatividade. Petrópolis: Vozes, 1994.

MORROW, R. Allen; TORRES, C. Alberto. Teoria Social e Educação. Porto: Edições Afrontamento, 1997.

QUEIROZ, Zuleide Fernandes de. Em cada sala um altar, em cada quintal uma oficina: o tradicional e o novo na educação tecnológica no Cariri Cearense. Fortaleza: Edições UFC, 2007.

ROSTOW, W.W. Theorists of Economic Growth from David Hume to the Present with a Perspective on the Next Century. New York: Oxford University Press, 1990.

SANTOS, Boventura de Sousa. O Estado e a sociedade em Portugal: 1974-1988. Porto: Edições Afrontamento, 1990. 
SCHUMPETER, J. A. Capitalismo, socialismo e democracia. Traduzido por Sérgio Góes de Paula. Rio de Janeiro: Zahar Editores, 1984.

STUBBS, Richard; UNDERHILL, Geoffrey R.D. Political Economy and The Changing Global Order. New York: St. Martin's Press, 1994.

TACHIZAWA, Takeshy. Gestão Ambiental e Responsabilidade Social Corporativa: estratégias de negócios focadas na realidade brasileira.São Paulo:Atlas, 2002.

VIANNA, Heraldo Marelim. Fundamentos de um Programa de Avaliação Educacional. Brasília: Liber Livro Editora, 2005.

VIEIRA, Sofia Lerche; ALBUQUERQUE, Maria Gláucia Menezes. Política e planejamento educacional. Fortaleza: Edições Demócrito Rocha, 2001.

\footnotetext{
'A Lei advinda da Política Nacional de Educação Ambiental estabeleceu como conceito da educação ambiental não-formal as ações e práticas educativas voltadas à sensibilização da coletividade sobre as questões ambientais e à sua organização e participação na defesa da qualidade do meio ambiente, devendo o Poder Público, em níveis federal, estadual e municipal, incentivar a ampla participação da escola, das universidades e de organizações não-governamentais na formulação e execução de programas e atividades vinculadas à educação ambiental não-formal. Neste particular, destaca-se o papel das Universidades, vez que são um canal de embasamento teórico, possuindo maior conhecimento da comunidade onde estão inseridas. Nestes termos, a Educação Ambiental é um componente essencial e permanente da educação nacional, devendo estar presente, de forma articulada, em todos os níveis e modalidades do processo educativo, em caráter formal e não-formal (Art. $2^{\circ}$ ). O artigo $5^{\circ}$ da Lei 9.795/99, destaca: a democratização das informações ambientais; o estímulo e o fortalecimento de uma consciência crítica dos problemas ambientais e sociais; a defesa da qualidade ambiental como um valor inseparável do exercício da cidadania; o fortalecimento da cidadania e a solidariedade como fundamentos para o futuro da humanidade. Assim, o compromisso das Universidades refere-se à promoção da inclusão social por meio da oferta de ensino de qualidade ao maior número possível de pessoas.

ii É cada vez maior o número de empresas européias que promovem estratégias de responsabilidade social em reação a diversas pressões de natureza social, ambiental e econômica. Desde 1993 há apelos para que participem da luta contra a exclusão social. No ano de 2000, a União Européia lançou o Livro Verde para incentivar práticas sócio e ambientalmente responsáveis.

${ }^{\text {iii }}$ No Brasil, por exemplo, algumas universidades como as Universidade de Brasília (UNB), Universidade de São Paulo (USP) e Universidade de Fortaleza (UNIFOR) abriram setores específicos para a educação ambiental.
} 


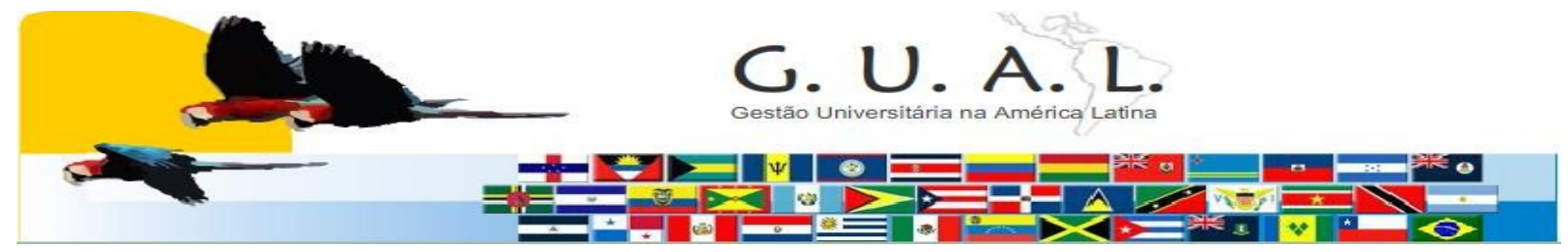

ISSN 1983-4535

\title{
THE PUBLIC POLICIES OF TECHNOLOGICAL HIGHER EDUCATION AND THE ISSUE OF SOCIAL RESPONSIBILITY IN BRAZIL
}

Marcus Vinicius de Oliveira Brasil, Mestre

Universidade de Fortaleza/UNIFOR

mvobrasil@gmail.com

Maria Engracia Loiola, Mestre

Instituto Federal de Educação, Ciência e Tecnologia do Ceará/IFCE engracia.loiola@ig.com.br

Mônica Mota Tassigny, Doutora

Universidade de Fortaleza/UNIFOR

monica.tass@gmail.com

\begin{abstract}
This article aims to discuss the feasibility of public policies of technological higher education in Brazil and some of its prerogatives to the social responsibility of higher education institutions. In this direction, it was discussed the main public policies for technological education, in particular, highlighting the case of the State of Ceará and the technological possibilities of higher education to be a principle of polytechnic. It was a documentary and a bibliographical research. It is concluded that public policies of technological higher education in our country have advanced training qualified people to the job's world, but there is still a missing link between theory and praxis of social responsibility that needs to be recovered as a sine qua non condition for the legitimacy of an effective state policy.
\end{abstract}

Keywords: Higher education. Technological teaching. Public policies. Social responsibility. 